\title{
Effect of Donor Simvastatin Treatment on Gene Expression \\ Profiles in Human Cardiac Allografts during \\ Ischemia-Reperfusion Injury
}

\section{Krebs, R.}

2019-04

Krebs , R , Kankainen, M , Holmström , E , Dhaygude , K, Lukac , J , Ojala , T, Mattila , P , Nykänen , A \& Lemström , K 2019 , ' Effect of Donor Simvastatin Treatment on Gene Expression Profiles in Human Cardiac Allografts during Ischemia-Reperfusion Injury ' , Journal of Heart and Lung Transplantation , vol. 38 , no. 4, Supplement , pp. S75-S76 . https://doi.org/10.1016/j.heal

http://hdl.handle.net/10138/313827

https://doi.org/10.1016/j.healun.2019.01.171

cc_by_nc_nd

acceptedVersion

Downloaded from Helda, University of Helsinki institutional repository.

This is an electronic reprint of the original article.

This reprint may differ from the original in pagination and typographic detail.

Please cite the original version. 


\title{
Effect of Donor Simvastatin Treatment on Gene Expression Profiles in Human Cardiac Allografts During Ischemia-Reperfusion Injury
}

\author{
R. Krebs ${ }^{1}$, M. Kankainen², E. Holmström¹, K. Dhaygude ${ }^{1}$, J. Lukac ${ }^{1}$, T. Ojala², P. Mattila², A. \\ Nykänen ${ }^{1}$, K. Lemström¹. \\ ${ }^{1}$ Transplantation Laboratory, \\ University of Helsinki, Helsinki, Finland, \\ ${ }^{2}$ Institute for Molecular Medicine Finland, University of Helsinki, Helsinki, Finland.
}

\section{Purpose}

Numerous studies have shown that statin therapy initiated early after heart transplantation has beneficial effects on the development of cardiac allograft vasculopathy. Recently, we were able to show in a randomized clinical trial that simvastatin treatment of brain-dead donors conditions the heart transplant to withstand ischemia-reperfusion injury and to reduce the need for rejection treatments early after transplantation. In this study, we analyzed myocardial gene expression profiles in cardiac allografts after donor simvastatin treatment.

\section{Methods}

84 heart transplant donors received $80 \mathrm{mg}$ of simvastatin via nasogastric tube $(n=42)$, or no treatment $(n=42)$ in a prospective, double-blinded randomized controlled trial. Transmural Tru-Cut biopsies were taken from the apex of left ventricle of the donor heart immediately before reperfusion and 1 hour after reperfusion. 20 heart biopsies from donors without treatment and 20 heart biopsies from donors with simvastatin treatment will be analyzed with RNA sequencing.

\section{Results}

The preliminary analysis of RNA sequencing data from myocardial biopsies revealed altogether 137 significantly differentially expressed genes in all pairwise comparisons. The overall biological functions of these genes were related to gene ontology terms such as response to toxic substance, leukocyte migration, neutrophil mediated immunity, response to lipopolysaccharide, and response to oxidative stress. At the KEGG pathway level, our results indicated alterations in IL-17, TNF, MAPK and the AGE-RAGE signaling pathways.

\section{Conclusion}

We have shown in previous studies that donor simvastatin treatment induces protective effects against IRI in heart transplant recipients. In this study, we were able to detect significantly differentially expressed genes related to effects of simvastatin treatment. In order to single out genes that show beneficial effects of simvastatin treatment, further analysis will be conducted by exploring gene expression changes in specific biological functional categories, such as interleukin signaling and neutrophil degranulation. The complete analysis will be presented at the ISHLT 2019 congress. 